\title{
The educational and supportive needs of informal caregivers working at Refentse Clinic, Hammanskraal
}

\author{
MS Richter, D Cur, Faculty of Nursing, University of Alberta, Canada. \\ (Take note: during the course of the study: Lecturer: Department of Nursing \\ Science, University of Pretoria). \\ D Peu, M Cur, Department of Nursing Science, University of Pretoria.
}

\section{Summary}

Informal caregivers have long been used as health care providers. It is also not uncommon in present days, to see such practice in the community. This practice of caring normally occurs within the context of the family. The purpose of the study is to explore and describe the educational and supportive needs of informal caregivers. This will assist in planning and establishing health education programmes and a supportive network, for the informal caregivers at Refentse clinic, at Hammanskraal.

A qualitative, explorative and descriptive design was followed, to collect the data. Participants in this study were informal caregivers, who were involved in Refentse clinic and resided in Stinkwater village. The method of choice, to gather data, was focus groups. An unstructured interview with a schedule was followed. Tesch's method was used, to analyse the data.

The results indicated that the informal caregivers' educational needs were mostly concentrated on health promotion and disease prevention activities. Their needs concerning support, mainly concentrated around support from government, the community, the University and the Primary Health Care clinic, in the area where they are serving. Personal needs focussed on recognition and respect.

\section{Introduction}

Informal caregivers have long been used as health care providers. At present it is also not uncommon, to see such practice in the community. Informal care normally occurs within the context of the family. If informal caregivers are forced to take over tasks, which were traditionally performed by formal caregivers, the question: "How will community nurses support informal caregivers?" arises. Available evidence suggests that community nurses can make a significant contribution, to support informal caregivers. However, very few informal caregivers have contact with community nurses, unless some event such as a medical crisis occurs.

\section{Background and significance of the problem}

Informal caregivers are pillars within their own communities. Their participation in the health care system compensates for shortage of manpower, in provision of health care. It is not unexpected, that the boundaries between informal caregivers and community nursing are increasingly being shaped by two key trends: the move from institutional to home-based care, and the growing emphasis on patient participation within health care in general, and nursing in particular. The emphasis on home-based care is increasing because of demographic changes. There is an increasing number of elderly people and people with chronic illnesses in the community. Escalating health care costs and the search for cost-effective alternatives to hospitalization, a desire to minimize the problems associated with hospitalisation, specifically hospital-acquired infections and the psychological trauma of a hospital stay, all contribute to this change. Home-based care is an awareness that most people prefer to stay at home, where they can exert more control over their lives. This practice will assist acute hospitals, to cope with proper care to acutely ill patients' care. In addition, home-based care decreases emphasis on institutional care in all sectors and emphasizes the recognition of the importance, of providing consumer choice (Kirk, Glendinning \& Glendinning 1998: 370).

In normal situations, the family is usually central in the provision of informal care. Within the community, the responsibility for providing more intensive personal and inti- 
mate care is likely to fall upon close family members in general and on one family member in particular. It is mainly female relatives who take part in the tasks of caring. This is provided on an unpaid basis, based upon feelings such as obligation and love.

If informal caregivers are forced to take over tasks that were traditionally performed by formal caregivers, the question: "How will community nurses support informal caregivers?" arises. The available evidence suggests that the community nurses can make a significant contribution. They can support informal caregivers, if there is a need. However, very few informal caregivers have contact with the community in the event of a medical crisis. Kirk et al (1998: 375) argue that community nurses have a relative lack of information, concerning the on-going support of informal caregivers. It is apparent, that the educational and informational needs of informal caregivers have been largely ignored in the past. Atkinson (1992: 835 - 840) mentioned, in his study on caregivers, that informal caregivers do not get any instructions; in relation to the caring activities they perform.

A change in the attitude and style of community nurses is needed. A change should be made from a compliance approach, to one of empowerment and partnership, with the community. The development of participation in care and relationships, built on a philosophy of partnership, is largely at the discretion of the nurse, as the party holding the greater power in professional-lay relationships (Trnobranski 1994: 733 - 737, Darbyshire \& Morrison 1995: 26 - 28, Rodwell 1996:305 - 313, Cahill 1996: 560 - 571). Nurses may perceive lay participation in care giving as threatening, especially when it includes the rendering of activities traditionally associated with professional nursing. Nurses should act as expert resources to informal caregivers. The increased participation of informal caregivers can offer opportunities for role enhancement and the development of interpersonal skills. A shift from a compliance approach, to one of empowerment and partnership, is needed (Coates \& Boore 1995: 628-640).

Although informal caregivers are willing to render a service to the community, their needs are not known. There are also no formal educational and supportive programmes, to assist them in Refentse clinic, at Hammanskraal. Therefore, their needs need to be explored and described. Knowledge of these needs will consequently enable the researchers to plan and establish health education programmes. These will cater for the community and the informal caregivers. Furthermore, lack of educational and supportive programmes necessitated research of this nature.

\section{Definition of terms}

Informal caregivers: They are a variety of community members, who are selected and trained, and work in the community they are living in. The informal caregiver carries out one or more functions, related to health care delivery and welfare. They are trained in some way, in the context of the intervention, but usually have no formal professional cer- tificate, or tertiary education (Friedman 2002: 162).

Health promoting: This is the process of enabling people to take control of their own health needs.

\section{Purpose of the study}

The purpose of the study was to explore and describe the educational and supportive needs of the informal caregivers at Refentse clinic, at Hammanskraal, on which a programme could be based.

\section{Objective of the study}

- to explore and describe the educational and supportive needs of the informal caregivers from the Refentse clinic, at Hammanskraal

- to make recommendations, for a supportive and educational programme for informal caregivers from the Refentse clinic, at Hammanskraal

\section{Research design}

A qualitative and descriptive design was used in this study.

\section{Population}

The population consisted of informal caregivers, who were involved with Refentse clinic, and reside in Stinkwater village, in the Hammanskraal district. Refentse clinic is situated in the rural community of Stinkwater village, north of Pretoria. The village has a community with diverse cultures, who are willing to serve their own people. This clinic serves the population of approximately 80000 and the services are rendered 24 hours per day.

Different categories of health care providers, including informal health care givers, provide primary health care to individuals, families and groups. The participation and involvement of the informal caregivers and the community influence the provision of primary health care in this community. According to Dennil, King and Swanepoel (1999: 67) primary health care services should be accessible, affordable, available, effective, and efficient. People should also have equal access to basic health care and social services. There is a need to investigate the needs of informal caregivers that influence their participation and involvement

\section{Sampling}

A purposive sampling method was used. This involved conscious selection, by the researchers, of certain subjects or elements, needed to be included in the study. The participants were purposely selected, particularly willing individuals. Cases were handpicked (Burns and Grove 1993:284). The informal caregivers, who regularly provide the services, were included in the study to provide the information necessary for the study. Sixteen informal caregivers took part. 


\section{Research instrument and data collection}

Focus groups were the method of choice, to gather data. A focus group interview can be defined as a qualitative technique, using discussion among a group of $4-12$ people, in a comfortable, non-threatening environment, to explore topics, or obtain perceptions about a given problem or topic of interest. The technique makes use of group interaction, to provide insight and data, which is not accessible without the stimulus of the group discussion (Bulmer 1998: 34, McDaniels \& Bach 1994:4, McDaniels \& Bach 1996: 53).

McDougall (1999: 48) provides a further description: “Group discussions which are semi-structured, with open questions by a facilitator, around a topic or area of experience". The governing concept is, that the whole is greater than the sum of its parts. A small group interview holds more information, than interviewing individuals separately (Reiskin 1992: 198). Two focus groups were held, with the same group of informal caregivers. An unstructured interview with a schedule was followed. The data was transcribed verbatim, within 72 hours after the focus group met. The participants were also asked to keep a reflective diary of their needs.

\section{Ethical considerations}

The Ethics Committee of University of Pretoria evaluated the proposal for approval. Permission was also obtained from the concerned authorities from North West Province (from Jubilee district).

Principles of research ethics, ethical dilemmas and code of ethics were always observed. All participants were respected and treated with dignity. They were treated like autonomous agents and given the opportunity to control their activities and to make informed voluntary decisions (Polit \& Hungler 1995:122-124). The participants were provided with consent forms to complete, before the commencement of the study. The completion of the consent form was voluntary to all participants. The participants were treated fairly and privacy was maintained. Promises of confidentiality to subjects were guaranteed (Polit \& Hungler 1997:124126).

The researchers avoided any harm to participants. The participants were informed that they could terminate participation at any time, if they wanted. The participants were assured that the information would not be used against them, in any way (Polit \& Hungler 1997:119-120). The participants were fully informed about the purpose of the study, type of data and procedure, as well as their rights regarding participation (Polit \& Hungler 1997:132-143).

\section{Data analysis}

Tesch's (Ross \& Rallis (1998) in Creswell 2003:192) analysis process was used, to analyse the data. The following eights steps were followed:
- The researchers formed a sense of the whole, by reading through all the transcripts. Some ideas were jotted down.

- $\quad$ One interview was chosen to start the analysis. Thoughts were written down as they occured.

- The researchers completed this, with several of the respondents' transcribed interviews. A list was compiled, of all found topics. Similar topics were clustered together and formed into columns. The columns were arranged according to major topics.

- The topics were then taken turned back to the original, transcribed data. The topics were abbreviated as codes and the codes written on the appropriate segments of the text.

- The researchers found the most appropriate descriptive wording for the topic and turned these into categories. Grouping topics that relate to each other reduced the total number of categories.

- The researchers made a final decision on the abbreviation for each category and alphabetised the codes.

- $\quad$ The data material that belonged to each category was assembled and a preliminary analysis performed.

- Each researcher coded the data independently and then compared the results (De Vos 1998: 344 and Creswell 2003:192).

\section{Strategies to increase the trustworthiness of the focus group data gathering methodology}

\section{Credibility strategies}

A strategy, used in this study, was prolonged engagement; an extended period of time was spent with the participants. It allowed the researchers to check perceptions and allowed informants to become accustomed to the researchers. Reflexivity was another technique that was used. This refers to the assessment of the influence of the investigator's own background, perceptions and interests, on the qualitative process. After each focus group met, the researcher reflected on the data collection. Field notes of each focus group were kept, for the purpose of audibility (Krefting 1991: 218). Audibility

\section{Triangulation}

"Triangulation is based on ideas of convergence of multiple perceptions, for mutual confirmation of data, to ensure that all aspects of a phenomenon have been investigated" (Krefting 1991: 219).

Multiple triangulation was used in this study i.e. method and investigator triangulation. "Investigator triangulation is considered to have occurred when each investigator has 
Table 1 Themes and sub themes, identified during the data analysis phase

\begin{tabular}{|c|c|}
\hline CATEGORY & EDUCATIONAL NEEDS \\
\hline SUB-CATEGORY & HEALTH PROMOTION \\
\hline THEMES & SUB-THEMES \\
\hline Family care & $\begin{array}{ll}- & \text { Care of children } \\
- & \text { Care of disabled people } \\
- & \text { Care of the aged } \\
- & \text { Care of the abused }\end{array}$ \\
\hline Poverty alleviation & $\begin{array}{l}\text { Provision of food and clothing } \\
\text { Care of poor families } \\
\text { Care of disadvantaged children } \\
\text { Gardening project }\end{array}$ \\
\hline $\begin{array}{l}\text { Training and development } \\
\text { Needs of the informal caregivers. } \\
\text { Strategies to provide the educational program }\end{array}$ & $\begin{array}{ll}- & \text { HIV/AIDS counselling } \\
- & \text { Development of communication } \\
- & \text { First Aid } \\
- & \text { Basic nursing care } \\
- & \text { Precautionary methods when handling blood } \\
- & \text { Community advise } \\
- & \text { Home-based care } \\
- & \text { Use of songs } \\
- & \text { Formal lessons } \\
- & \text { Use of pamphlets and books } \\
- & \text { Drama } \\
- & \text { Workshops } \\
- & \text { Home visits } \\
- & \text { Observational method } \\
- & \text { Build partnerships } \\
- & \text { Empowerment strategies } \\
- & \text { Group effort } \\
- & \text { School programs } \\
- & \text { Role play }\end{array}$ \\
\hline Community development & $\begin{array}{ll}- & \text { Gardening project } \\
- & \text { Drama } \\
- & \text { Empowerment of abused members of families } \\
- & \text { Prevention of crime } \\
- & \text { Health information centre }\end{array}$ \\
\hline Nutrition & $\begin{array}{ll}- & \text { Provision of food } \\
\text { How to apply for grants } & \text { Help mothers who receive grant to use it properly }\end{array}$ \\
\hline Family planning, pregnancy and antenatal care & $\begin{array}{ll}- & \text { Care of pregnant women } \\
- & \text { Care of pregnant teenagers } \\
- & \text { Provision of family planning } \\
- & \text { Antenatal care }\end{array}$ \\
\hline
\end{tabular}

a prominent role in the study, the expertise of each investigator is different, and the expertise (disciplinary bias) of each investigator is evident in the study" (Kimchi et al 1991 365). Each investigator in this study was present during data collection. The investigators used two different methods to obtain data, focus groups and reflective diaries.

Peer examination was also used. This implied that the researchers discussed the research process and findings with expert colleagues, who have experience with qualitative methods. This was done during a seminar, with colleagues at the Department of Nursing Science, University of Pretoria.

\section{Transferability strategies}

A dense description, on the background information about the informants and the research context and setting, was given. This allows other researchers to assess the transferability of the findings. 
Table 2 Themes and sub themes, identified during the data analysis phase

\begin{tabular}{|c|c|}
\hline CATEGORY & EDUCATIONAL NEEDS \\
\hline SUB-CATEGORY & DISEASE PREVENTION \\
\hline THEMES & SUB-THEMES \\
\hline $\begin{array}{l}\text { Prevention of HIV/AIDS and other sexually } \\
\text { transmitted diseases }\end{array}$ & $\begin{array}{ll}- & \text { Cause } \\
- & \text { Signs and symptoms } \\
- & \text { Cause of death } \\
- & \text { Prevention } \\
- & \text { Youth focus } \\
- & \text { Inform children about HIV/AIDS }\end{array}$ \\
\hline Prevention of chronic disease & $\begin{array}{ll}- & \text { Diabetes mellitus } \\
- & \text { Hypertension } \\
- & \text { Cancer } \\
- & \text { Psychiatric illnesses }\end{array}$ \\
\hline Prevention of smoking, drugs and alcohol abuse & - Involvement of the community \\
\hline Prevention of TB & $\begin{array}{l}\text { Education on TB } \\
\text { Help people with TB }\end{array}$ \\
\hline Environmental and personal hygiene & $\begin{array}{ll}- & \text { Teach hygiene } \\
- & \text { Education on health }\end{array}$ \\
\hline Prevention of mother to child transmission & Need more information \\
\hline
\end{tabular}

\section{Dependability strategies}

The exact methods of data gathering and analysis were described. It gave a dense description of how repeatable the study might be. The term audibility is used in qualitative methods, to describe the situation in which another researcher can clearly follow the decision trail used by the investigator.

Another method, used in this study to enhance the trustworthiness, is the code/recode procedure. The two researchers independently coded and recoded the data. The results were compared for differences.

\section{Confirmability strategies}

Confirmability strategies include triangulation techniques and confirmability audits, as discussed previously.

\section{Data interpretation and literature verification}

Themes and sub themes, identified during the data analysis phase, are as depicted in table 1 and 2.

The category on educational needs mainly centred around two themes, namely health promotion and diseases prevention. This was not a surprise, because the informal caregivers are confronted with these problems on a daily basis. It is a reality of their daily lives and the communities they live in. The Health Systems Trust indicate that: "training of community based health care workers (CBHWs) (and in this case informal caregivers) should be a continuous, community-based, problem-orientated, experiential education process. Apart from an initial orientation course and short specific course(s) the training should be undertaken where CBHWs operate" (http://www. org.za/sahr/2002/). They also suggested that such a course should start with an intensive course and continue gradually over a few years. Courses should then extend their range, as the $\mathrm{CBHW}$ becomes more competent.

\section{Health promotion}

Health promotion is the process of enabling people to take control of their own lives. O' Donnel (1987) in Mandle 2002:12, defines health promotion as the science and art of helping people to change their lifestyle, to move towards a state of optimal health. The informal caregivers need education concerning health promotion. Their education should concentrate on family care, poverty alleviation, community development, nutrition, and family planning, pregnancy and antenatal care.

Family care remains an important aspect in both rural and urban homes. It is the responsibility of a health care worker or informal caregiver, to educate the families on how to care for themselves. In Friedman (1998: 100) it is stated that the family is a system, with different structural functions. The family care for their children, their disabled members, the aged, and abused members of the family. It is important to empower the families with skills, to care for each other. The participants in this study emphasized that working with families is a priority. In view of the above comment, family 
care is a comprehensive concept, where members are cared for to promote health and to preserve the lives of their own family members. Friedman (1998:100) indicates that a homeostatic family renders both formal and informal roles.

Poverty is largely a rural phenomenon. This is also manifested in this study. The poor are people, trapped in a cycle of being poor, weak, isolated, powerless and vulnerable. Poverty alleviation is one of the big challenges of today (De Beer \& Swanepoel 2000: 7). An important aspect of poverty alleviation is to teach the informal caregivers the process of conscientisation - a concept developed by Paolo Freire, an educational liberationist. According to Freire, people must critically reflect on their circumstances and question it. Only then development will happen and poverty will be alleviated. The informal caregivers can be taught the process of introspection, critical reflection and development in changing the lives of the individuals, families and groups.

Training and development are important elements of empowering individual participants. During training, concemed members learn how things are done and applied, through involvement and participation. In training, members gain expert power to provide others with relevant information. Smith and Cronje (1997:249) define expert power as: the power based on knowledge and expertise. A leader who possesses this power has special power, over those who need the knowledge, especially in training. In this study, training and development were the main focus points, emphasized by participants. The participants identified several strategies for empowering informal caregivers and the families. Those strategies are:

- $\quad$ The use of drama
- $\quad$ Forkshops
- $\quad$ HIV/AIDS counselling
- $\quad$ Communication skills
- $\quad$ Use of pamphlets
- $\quad$ Use of comy language
-

The participants indicated that these strategies would ease the need for education in the community. Drama or roleplay gives individuals insight into the handling of real life situations. In this study, the informal caregivers will be able to control their own environment due to the insight they gained, in handling situations (Mellish \& Brink 1986: 165166). With regard to formal lessons, participants indicated that they must be provided with education (HIV/AIDS, basic nursing care and communication skills) and guidelines on how to give a formal lesson.

The participants also emphasized home-based care, as a strategy to promote healthy living. More emphasis should be put on providing information on how home based care should be provided. As indicated by the Department of Health (2001:1-3), home based care calls upon the resources and skills within the community. It should be directed to chronic and acute diseases such as HIV/AIDS, and other debilitating diseases. The participants volunteered to fill this care-giving role. In this way they can assist the government in preventing diseases and promoting health. This shows that the community members have an interest in dealing with their own health problems.

\section{Disease prevention}

The educational needs of the informal caregivers, concerning the prevention of diseases, was as follows: prevention of HIV/AIDS and other sexually transmitted diseases, prevention of chronic disease, prevention of drugs, alcohol and smoking addiction, prevention of tuberculosis, and environmental and personal hygiene.

It is important that the role of informal caregivers be developed, to deal with HIV/AIDS. Figure 1 demonstrates a comprehensive community model, showing how informal caregivers (IFC) could assume the role of co-ordinating and providing community based support, to ailing adults and children infected with AIDS, including AIDS orphans. This model was developed by Friedman (2002: 177) for the South African population and was published in The South African Health Review for 2002. It is an applicable model for the training of the informal caregivers of this study. Figure 1 is self-explaining and concentrates on the support informal caregivers can render and the support that they will need. It is clear that informal caregivers (in HIV/AIDS care) can be used effectively and supported in various ways. They can be utilised to visit the sick, and give psychosocial support, to train family members to take care of their sick, and co-ordinate services. The types of support, which they can render in the community, are shown in the last column on the right in Figure 1.

The need for caring for the chronically ill was a focal interest of the participants' discussions and concerns. It was agreed that monitoring of chronic conditions should be part and parcel of the informal caregivers' role. Therefore, there is a need for empowering these caregivers. Lack of skills, on caring for the chronically ill, may have an impact on the survival of the community concerned.

Tuberculosis is one of the major communicable diseases present in South Africa. Informal caregivers can successfully be involved in the DOTS (Direct observed treatment short course) program. DOTS is the only globally recognised strategy, for effective TB control. Treatment supporters observe patients, as they take their drugs daily. The DOTS strategy is a patient-centred approach. It provides support to TB patients, by observing them as they take their medication and ensuring that they complete their treatment. (1B South Africa's Health Priority 1997: 6). The implementation of DOTS ensures that every TB patient has the support of another person, to ensure that they take their medication daily. The treatment supporter does not have to be a professional health worker. This is where the informal caregivers can be used very effectively. A treatment supporter can be any responsible member of the community. (Department of Health 2001: 15). 
Figure 1 AN APPROACH TO INTEGRATING THE WORK OF INFORMAL CAREGIVERS IN AN HIVIAIDS ENVIRONMENT

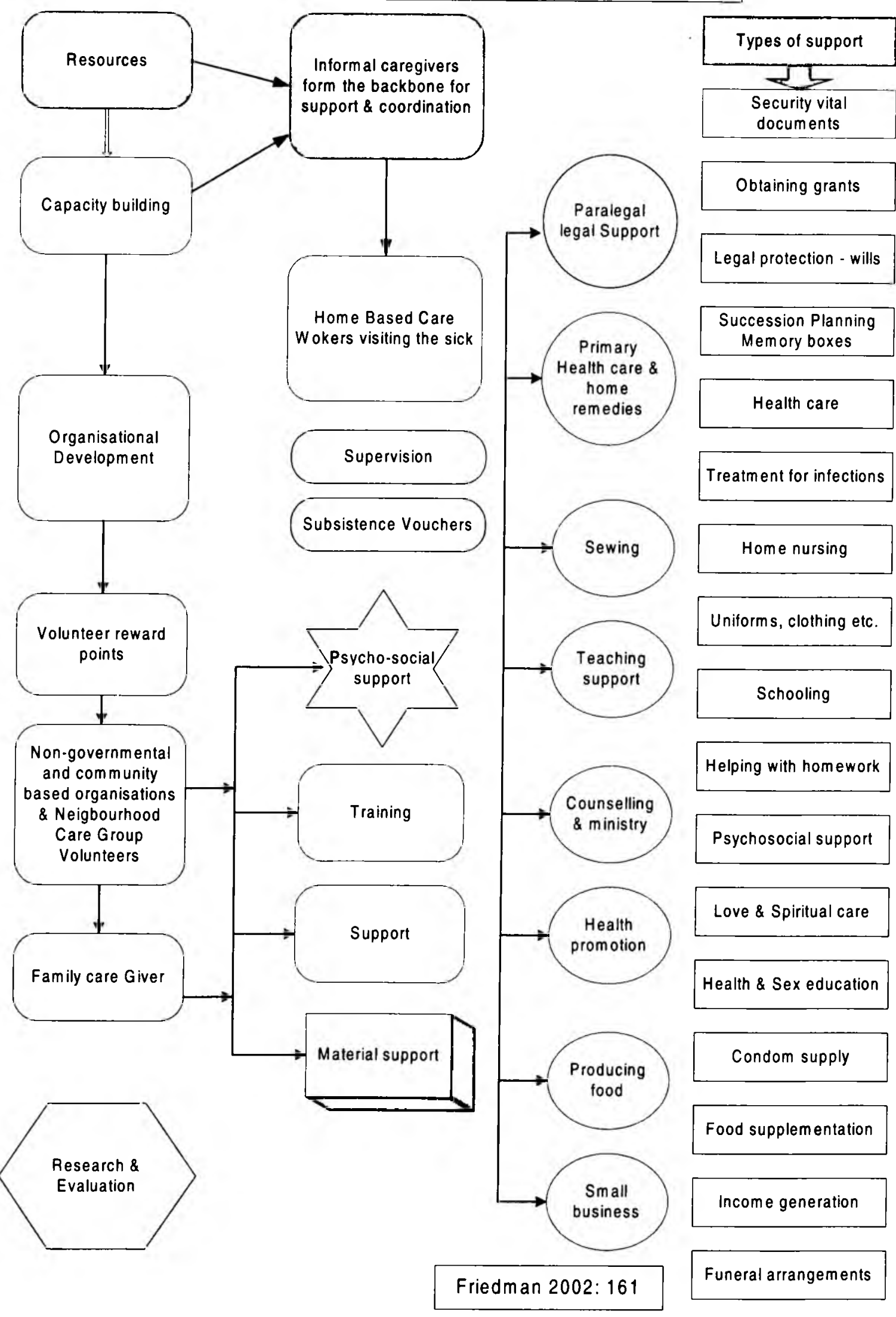


Table 3 Category B: Supportive needs

\begin{tabular}{|c|c|}
\hline THEMES & SUB-THEMES \\
\hline Governmental support & $\begin{array}{ll}- & \text { Provision of home based care materials } \\
- & \text { Finance } \\
- & \text { Organize workshops } \\
- & \text { Help with water } \\
- & \text { Give enough medicines } \\
- & \text { Empowerment } \\
- & \text { Need development } \\
- & \text { Care for the carers } \\
- & \text { Provide security }\end{array}$ \\
\hline Community support & $\begin{array}{ll}- & \text { Need your support } \\
- & \text { We need your help } \\
- & \text { Provide with security }\end{array}$ \\
\hline Clinic support & $\begin{array}{ll}- & \text { Change your attitude/behaviour } \\
- & \text { Need your support and help } \\
- & \text { We need your advice } \\
- & \text { Stop shouting at us } \\
- & \text { Take us as people } \\
- & \text { You are there to help us if not so do not stay } \\
- & \text { Avoid gossip }\end{array}$ \\
\hline UPsupport & $\begin{array}{l}\text { Do research and find out how people are liv } \\
\text { ing from different places (cultural issues) } \\
\text { Request partnership during health education } \\
\text { program } \\
\text { - } \quad \text { Financial help for transport }\end{array}$ \\
\hline Recognition & $\begin{array}{ll}- & \text { Certification } \\
- & \text { Name tag } \\
- & \text { Identification } \\
- & \text { Work as partners } \\
\text { UP to send more students to work with for } \\
\text { recognition }\end{array}$ \\
\hline Workshops & $\begin{array}{ll}- & \text { Need more workshops on home based care } \\
\text { - } & \text { Variety of workshops }\end{array}$ \\
\hline Communication & Free and fair \\
\hline Respect & $\begin{array}{ll}- & \text { Need respect from the community } \\
- & \text { Need respect from students } \\
- & \text { Nurses should care for us }\end{array}$ \\
\hline
\end{tabular}

What can the informal caregiver do? First of all, they can increase community awareness of the right of all, to free access, to effective TB care. Secondly they can make friends, neighbours and colleagues aware of DOTS. They can contribute to awareness of how our country's national Tuberculosis programme can save lives and prevent the spread of TB. (Facts 2001: 13)

Environmental and personal hygiene are the most important elements that contribute to the survival of the community and the caregivers. A skilled caregiver will be able to assess environmental conditions such as food and other lifestyle influences and determine whether their own environmental needs are satisfactorily met. Lundy and Janes (2001:22) indicate that the environment has been a concern for nursing since the days of Florence Nightingale. It is still the concern of the government and non-governmental organizations, to make providing a healthy environment a priority. This can be achieved through the involvement and participation of the community, making use of informed caregivers.

The informal caregivers' needs, concerning support, mainly concentrated around support from the government, the 
community, the university and the PHC clinic, in the area that they serve. Personal needs, concerning support, focussed on recognition and respect.

As already indicated, there is a need for support from the government, the community (including nurses), and from the University of Pretoria. This will enhance the collaborative efforts of all the parties, regarding health promotion and illness prevention. The support that was emphasized was:

- Financial,

- Material,

- $\quad$ Security.

- The aspect of finance, especially concerning the government, were:

- Money for workshops,

- $\quad$ Buying materials.

This shows that money is the vehicle that drives everything. Without money, many things are impossible, particularly if you deal with empowerment of the communities. Materials could only be available if provided and kept safe.

Security was one of the main focuses because caregivers are threatened by the rate of crime in the community. The group reached consensus that security is their first priority, before one can deliberate on anything. Violence is a barrier in the promotion of health. According to Lundy and Janes (2001: 494) violence has been part of humankind's world at least since recorded history. It remained primarily a criminal justice issue. However, the community should take into consideration that, without the help of the community concerned, violence is difficult to handle. Caregivers must participate in the efforts to reduce crime within their communities.

Informal caregivers need to be willing and able to take additional responsibility, without getting extra remuneration (whether physical, social, emotional or material). The aim of the inclusion of informal caregivers in health care activities is to enhance community participation and involvement and to promote health and community empowerment. This will ensure that there are individuals who can be held responsible for their own health, and that of the members of the community. (Kirk et al1998: 376).

According to De Vos (1997: 407) community participation leads to the creation of a democratic system and procedure, which enables community members to become actively involved and to take responsibility for their own development. In this way, all share equally in the fruits of community development and their decision making power is improved. It provides a sense of belonging or identity, a commitment to common norms, a willingness to take responsibility for oneself and others, and a readiness to share and interact. The end product is community empowerment, the process of increasing personal, interpersonal and political power, enabling individuals, singly or collectively, to improve their life situation. Empowerment increases the energy, motivation, coping and problem-solving skills, de- cision-making power, self-esteem, self-sufficiency and selfdetermination, of community members (Kirk et al 1998: 373).

Swanepoel and De Beer (1998: 32-33) state that the goal of a project, like the one described in this article, is not to reach the project's concrete needs, but to enable the people (in this case the informal caregivers) to fulfil their abstract human needs, to enhance the learning process, and to help them to gain meaningful empowerment. The attitude of a researcher or community development worker should be to have respect for the knowledge and wisdom of the people. Some of them might be illiterate, or not well educated, but it does not follow that they are ignorant. The people, and their views and feelings, must be respected. They must be treated as human beings. The role of the researcher and community worker is that of guide, advisor, advocate, enabler and facilitator.

\section{Recommendations}

In view of the data interpreted and verified, various recommendations can be made. The following recommendations serve as the basis for concluding this study:

- The establishment of a health promotion training programme for informal caregivers is necessary. The programme will provide informal caregivers with information that will assist in the empowerment of the community, thus promoting health.

- $\quad$ Poverty alleviating strategies, that will include massive collaboration, are recommended. The community will be able to take ownership of their own projects to prevent poverty.

- Encouraging the community to establish various projects and promoting participation, especially in gardening, will render long term benefits. Skills in gardening e.g., will be transferred to the community.

- Collaborative support from the clinic, community, government and non-government organizations is necessary. Collaboration, in the form of the establishment of projects, will be encouraged.

- Informal caregivers in health promotion programs must receive recognition. Informal caregivers could be given an opportunity to run the health education programmes at schools.

- Informal caregivers must be recognized as members of the multidisciplinary health team. They could participate in the planning of educational programmes.

\section{Conclusion}

Informal caregivers are part and parcel of the primary health care team. It was necessary to investigate and to describe the educational needs of the caregivers in rural communities. This investigation will enable the researchers to plan and establish educational programmes, in the community of Hammanskraal. Valuable information was gained, which may also be applicable to other rural settings in our country. In this way more communities may benefit from the results of this research. 


\section{List of sources}

ATKINSON, FI 1992 : Experiences of informal cares providing nursing support for disabled dependents. Journal of Advanced Nursing, 17: $835-840$.

BULMER, C 1998: Clinical decisions: defining meaning through focus groups. Nursing Standard. 12(20): $34-36$.

BURNS, N \& GROVE, SK 1993: The practice of Nursing Research: Conduct. Critique \& Utilization. Philadelphia: W.B Saunders Company. Second Edition.

CAHILL, J 1996: Patient participation: a concept analysis. Journal of Advanced Nursing. 24: 560-571.

COATES, V \& BOORE, J 1995: Self-management of chronic illness: implications for nursing. International Journal of Nursing Studies. 32(6): 628-640.

DARBYSHIRE, P \& MORRISON, H 1995: Empowering parents of children with special needs. Nursing Times, 91(32): 26-28.

DE BEER, F \& SWANEPOEL, H 2000: Introduction to Developmental Studies, Oxford: Oxford University Press.

DENNIL, K; KING, L \& SWANEPOEL, T 1999: Aspects of Primary Health Care. Johannesburg: International Thomson Publishing(Southern Africa) (Pty) Ltd.

DEPARTMENT OF HEALTH. 2001: National guideline on home-based care \& community -based care. Supplement Journal of Nursing and Midwifery.

DE VOS, AS 1998 : Research at Grass Roots. Goodwood: Academica.

FACTSSHEETS ON HIV/AIDS FOR NURSES AND MIDWIVES. 2001: Africa Journal of Nursing and Midwiferv, 3(1): 10-14.

FREIRE, P 1993: Pedagogy of the Oppressed. London: Pengiun Books.

FRIEDMAN, MM 1998: Family Nursing: Research, Theory and Practice. Connecticut: Apple \& Lange. Fourth Edition.

FRIEDMAN, 12002 : Community Based Health Workers. South African Health Review 2002. http:// www.org.za/sahr/2002/

KREFTING, L 1991: Rigor in Qualitative Research: the Assessment of Trustworthiness. The American Journal of Occupational Therapv. 45(3): 214-222.

KIMCHI, J ; POLOVKA, B \& STEVENSON, JS 1991 : Triangulation: Operational Definitions. Nurs- ing Research. $40(6): 364-366$.

KIRK \& GLENDINNING,S \& GLENDINNING, C 1998: Trends in community care and patient participation: implications for the roles of informal cares and community nurses in the United Kingdom. Journal of Advanced Nursing. 28(2): 370-381.

LUNDY, KS \& JANES, S 2001: Communitv Health Nursing. Caring for the Public.s Health. Massachusetts: Jones and Bartlett Publishers.

Mandle, E 2002: Health Promotion: Through the lifespan ( $5^{\text {th }}$ Edition) St. Louis:Mosby.

MCDANIELS, RW \& BACH, CA 1994: Focus Groups: A Datagathering Strategy for Nursing Research. Nursing Science Quarterly, $7(1): 4-5$.

MCDANIELS, RW \& BACH, CA 1996: Focus Groups: The Question of Scientific Rigor. Rehabilitation Nursing Research. 5(2): 53-59.

MCDOUGALL, P 1999: Focus groups: an overview of their use as a research method. Community Practitioner. 72(3): 48 - 49.

MELLISH, JM \& BRINK, H 1986: Teaching the practice of nursing. Durban: Butterworth.

POLIT, DF \& HUNGLER, BP 1997: Essentials of nursing research, methods, appraisals and utilisation. Philadelphia: Lippincott

TUBERCULOSIS. SOUTHAFRICA'S HEALTH PRIORITIES. 1997: Masiphile. 1(2): 4-7.

TRNOBRANSKI, PH 1994: Nurse-patient negotiation: assumption or reality. Journal of Advanced Nursing. 19: 733 - 737.

REISKIN, H 1992: Focus groups: a Useful Technique for research and practice in Nursing. Applied Nursing. 5(4): 197-201.

RODWELL, CM 1996: An analysis of the concept of empowerment. Journal of Advanced Nursing. 23: $305-313$.

SMITH, PJ \& CRONJE, GJ 1997: Management Principles. Pretoria: Juta and Co.Ltd.

SWANEPOEL, H \& DE BEER, F 1998: Community Capacity Building. A Guide for Fieldworkers and Community Leaders. Oxford; Oxford University Press. 